\title{
Eosinophilic inflammation in sputum of poorly controlled asthmatics
}

\author{
M. Romagnoli, I. Vachier, P. Tarodo de la Fuente, H. Meziane, C. Chavis, J. Bousquet, \\ P. Godard, P. Chanez
}

\begin{abstract}
Eosinophilic inflammation in sputum of poorly controlled asthmatics. M. Romagnoli, I. Vachier, P. Tarodo de la Fuente, H. Meziane, C. Chavis, J. Bousquet, P. Godard, P. Chanez. C) ERS Journals Ltd 2002.

ABSTRACT: Despite full effective treatment, asthmatic patients often present with poorly controlled asthma. Airway eosinophilia is associated with asthma, but its relationship with asthma control is still undetermined.

To investigate the relationship between airway eosinophilia and asthma control, cellular and biochemical markers of airway inflammation were measured in 19 subjects with poorly controlled asthma, 16 subjects with asthma under control and eight normal volunteers. The severity of asthma was mild-to-moderate persistent in 23 patients (14 poorly controlled) and severe prednisone-dependent in 12 subjects (five poorly controlled). Induced sputum was analysed for total and differential cell counts, leukotriene $\mathrm{E} 4\left(\mathrm{LTE}_{4}\right)$, eosinophil cationic protein $(\mathrm{ECP})$, regulated on activation, normal T-cell expressed and secreted (RANTES), and interleukin (IL)-8.

Sputum eosinophils, LTE 4 , ECP and RANTES levels (but not IL-8) were significantly higher in patients with poorly controlled asthma as compared to patients with controlled asthma. By contrast, sputum cells and sputum inflammatory markers were not different among groups of patients with different severity of asthma.

These results suggest that sputum eosinophilia is associated with poorly controlled asthma rather than with the severity of asthma.
\end{abstract}

Eur Respir J 2002; 20: 1370-1377.

\begin{abstract}
Clinique des Maladies Respiratoires, Institut National de la Santé et de la recherche médicale U454, Centre Hospitalier Universitaire-Montpellier, Hopital Arnaud de Villeneuve, Montpellier, France.
\end{abstract}

Correspondence: P. Chanez, Hopital Arnaud de Villeneuve, 34295 Montpellier Cedex 5, France.

Fax: 33467521848

E-mail: chanez@montp.inserm.fr

Keywords: Asthma control

asthma severity

eosinophils

induced sputum

Received: April 102002

Accepted after revision: July 292002

This study was supported in part by Direction de la Recherche Clinique (AOI 1995 no. 7515).
Asthma is a chronic inflammatory disorder of the airways that is clinically characterised by recurrent episodes of dyspnoea, wheezing and chest tightness, associated with variable airway obstruction [1]. Asthma severity may be defined by the amount of symptoms, the degree of airways obstruction (as evaluated by peak expiratory flow (PEF)) and forced expiratory volume in one second (FEV1), or by the need for $\beta$-agonist reliever therapy [1]. The severity of asthma represents the overall clinical history of bronchial asthma over a period of time, usually $1 \mathrm{yr}$. By contrast, control should take into account the recent history (i.e. 1 month or the last 14 days) [2]. Assessment of severity and control are thus retrospective. The severity of asthma is usually assessed at the first visit. Treatment of asthma is based on asthma severity, with a step-up approach, characterised by increased intensity of treatment for increased severity of asthma [1].

The primary goal of asthma treatment is the control of asthma, defined as the absence or presence of minimal symptoms, minimal or no requirement for rescue medications, and normal or best lung function [1]. Poor control of asthma is characterised by the persistence of symptoms, night awakening, use of rescue medications, and increased diurnal variability of PEF $(\triangle \mathrm{PEF}>20 \%)[3]$. Scores to assess asthma control have been reported recently [4-7].

The relationship between airway inflammation and asthma severity is controversial, particularly in severe asthmatics [8]. Sputum eosinophilia has been shown to correlate with asthma severity in some [9], but not other studies [10-12]. To the best of the authors' knowledge, the relationship between airway inflammation and asthma control has not been investigated.

It was speculated that the discrepancy between different studies might be related to the lack of proper assessment of the degree of asthma control in the different levels of asthma severity. To investigate the relationship between airway eosinophilia and asthma control, cellular and biochemical markers of airway inflammation were measured in 19 subjects with poorly controlled asthma, 16 subjects with asthma under control, and eight normal volunteers. The concentration of leukotriene E4 $\left(\mathrm{LTE}_{4}\right)$, eosinophil cationic protein (ECP), and regulated on activation, normal T-cell expressed and secreted (RANTES) in sputum supernatant was determined, in order to assess the potential activation of eosinophils. The level of sputum interleukin (IL)-8 was also determined to assess the degree of neutrophil activation. 


\section{Methods}

\section{Subjects}

Asthmatic patients, regularly followed in the authors' institution for at least $1 \mathrm{yr}$, were randomly recruited for the study over a period of 1 month, when attending the hospital for a scheduled visit. All subjects were outpatients, without any acute severe asthma exacerbation (defined by the requirement of treatment with oral glucocorticoids or a decrease in the morning PEF $>30 \%$ below the baseline value on two consecutive days) [13] in the month preceding the study. The diagnosis of asthma was established according to the American Thoracic Society criteria [1]. Subjects were considered atopic by positive skinprick tests to at least one common aeroallergen (wheal diameter $3 \mathrm{~mm}$ greater than saline control). Patients were excluded if they were smokers or exsmokers and if they had a respiratory infection within the month preceding the study, or if the FEV1 value was $<1 \mathrm{~L}$ [14]. At enrolment, they all underwent sputum induction and a pulmonary function test (flow-volume loop) was carried out before and during the sputum induction, using a Pneumoscreen (E. Jaeger Laboratories, Wurzburg, Germany). Normal volunteers were also enrolled in the study. None of them had any previous history of lung or allergic disease and were not using any medication. They had a normal lung function test $\left(\mathrm{FEV}_{1}>80 \%\right)$ and negative skin allergy test.

The study was approved by the Ethics Committee of the authors' institution, and subjects gave their written informed consent.

\section{Assessment of asthma control}

Patients were considered to have poor asthma control based on symptom frequency, night waking, bronchodilator use and PEF diurnal variability $>20 \%$, in the week preceding the study [3]. None of them presented with an asthma exacerbation, in particular none of them required unscheduled visits, and none of them showed a linear decline in PEF values without significant increase in PEF diurnal variability, as previously described in exacerbated asthmatics [3]. Diurnal PEF variation was calculated by the following formula [3]:

(evening - morning PEF/the mean of the evening and morning $\mathrm{PEF}) \times 100$

\section{Classification according to asthma severity}

Asthma severity was classified according to the National Heart Blood and Lung Institute/World Health Organization (NHLBI/WHO) Workshop on the Global Strategy for Asthma [1] and patients were classified as intermittent, mild, moderate and severe persistent asthmatics. The severity of asthma was evaluated in a prospective manner, with documented clinical events, lung function values and treatment in the year preceding the study, as previously recommended [15].

\section{Sputum induction}

Sputum was induced according to the method of PIN et al. [16]. Before sputum induction, all subjects underwent spirometry, with FEV1 and vital capacity measurements, before and $10 \mathrm{~min}$ after inhalation of $200 \mu \mathrm{g}$ salbutamol by metered-dose inhaler. Hypertonic saline (3, 4 and $5 \%$ saline) was nebulised with an ultrasonic nebuliser (DP 100 Syst'am; Paris, France). This nebuliser generates particles with a mean mass aerodynamic diameter of $4.5 \mathrm{~mm}$ and has an output of $2.4 \mathrm{~mL} \cdot \mathrm{min}^{-1}$. Subjects inhaled hypertonic saline solution for 5-min periods up to $30 \mathrm{~min}$, and were asked to rinse their mouth out with water before induction to avoid salivary contamination of induced sputum samples as much as possible. The concentration of saline was increased, if possible, at intervals of $10 \mathrm{~min}$ (two nebulisations of each concentration) from $3 \%$ to $4 \%$ to $5 \%$. Spirometry was repeated at 5-min intervals throughout the procedure and immediately after sputum induction was completed. At the end of the test, a nebulisation with bronchodilators was given. The concentration of saline was not increased if the FEV1 fell by $>10 \%$ from the postbronchodilator value. Sputum induction was discontinued if the FEV1 declined $>20 \%$ or if troublesome symptoms occurred (i.e. dyspnoea, wheezing, severe cough). Selected sputum plugs from saliva were then analysed [17].

\section{Sputum processing}

Sputum was processed as described previously [11]. The volume of the induced sputum plugs was determined and overlaid with an equal volume of $0.1 \%$ dithiothreitol (Sputalysin 10\%; Behring Diagnostics Inc., Somerville, NJ, USA). The sample was then gently mixed by vortex mixer and placed in a shaking water bath at $37^{\circ} \mathrm{C}$ for $30 \mathrm{~min}$ to ensure complete homogenisation. The homogenised sample was centrifuged (GR4.22; Jouan, St Herblain, France) at $2,000 \mathrm{rpm}$ for $10 \mathrm{~min}$. The supernatant was aspirated and frozen at $-80^{\circ} \mathrm{C}$ for later analysis. Phosphatebuffered saline was added to the cell pellets, which remained after centrifugation, and resuspended. Total cell counts were obtained after staining with MayGrunwald Giemsa on cytospin (Cytospin 2; Shandon, Runcorn, UK), by two blind observers.

\section{Biochemical measurements in sputum supernatant}

Aliquots of induced sputum were previously analysed using reverse phase-high performance liquid chromatography (RP-HPLC) as previously described [18]. The peaks obtained were co-eluted with standard solution and the only peak identifiable using HPLC was for $\mathrm{LTE}_{4}$ (detection limit $1 \mathrm{ng}$ ). This is the reason 
why only $\mathrm{LTE}_{4}$ levels were evaluated using an enzymelinked immunosorbent assay (ELISA) kit (Stallergènes, Anthony, France). The detection limit of the ELISA was $10 \mathrm{pg} \cdot \mathrm{mL}^{-1}$ and samples were diluted from one in 10 to one in 20. The concentration of ECP was determined using a commercial radioimmunoassay kit (RIA; Pharmacia-Upjohn, Uppsala, Sweden). The detection limit of the RIA was $2 \mu \mathrm{g} \cdot \mathrm{L}^{-1}$ and samples were diluted from one in four to one in 25. RANTES concentrations were measured with a quantitative sandwich enzyme immunoassay (EIA) technique (Quantikine; R\&D Systems, Inc., Minneapolis, MN, USA). The detection limit of the assay was $3 \mathrm{pg} \cdot \mathrm{mL}^{-1}$. IL-8 concentrations were measured by an EIA (Immunogenetics; Valbiotech, Paris, France). The detection limit of the EIA was $20 \mathrm{pg} \cdot \mathrm{mL}^{-1}$ and some samples were diluted to one in 10 .

\section{Statistical analysis}

Results are presented as median, 25th and 75th percentiles. The Kruskal-Wallis nonparametric test was used to evaluate the difference between the asthmatic groups and normal subjects. The Mann-Whitney U-test was then used to evaluate the difference between poorly controlled and controlled asthmatics and between mild-moderate and severe steroid-dependent asthmatics. The Dunn's multiple comparison post-hoc test was then performed. Analyses of correlation coefficients were calculated using the Spearman-rank test.

\section{Results}

\section{Characteristics of patients}

Thirty-five asthmatic patients, regularly followed in the authors' institution, ranging in age from 18 to $75 \mathrm{yrs}$, were recruited for the study. All patients were currently recording their asthmatic symptoms, twicedaily PEF values and short-acting $\beta_{2}$-agonist requirements and had been doing so for at least $1 \mathrm{yr}$.

Nineteen asthmatics were considered poorly controlled (table 1). As expected, they differed from controlled asthmatics by their symptom scores $\left(\right.$ days $\cdot$ week $^{-1}$ ), night waking (nights $\cdot$ week $^{-1}$ ), shortacting $\beta_{2}$-agonist requirements and diurnal PEF variability $(\mathrm{p}<0.001)$ in the week preceding the study, as shown in table 1 . FEV1 was no different between poorly controlled and controlled asthmatics.

The characteristics of patients according to asthma severity are presented in table 2 . The 23 mild-moderate persistent asthmatics (14 of them with poorly controlled asthma) were receiving regular beclomethasone dipropionate or equivalent (budesonide or fluticasone) daily (median dose $500 \mu \mathrm{g} \cdot \mathrm{day}^{-1}$ ). Ten of them were treated with regular long-acting $\beta_{2}$-agonists. The 12 patients with severe prednisone-dependent asthma (five poorly controlled) were treated by high doses of inhaled steroids (beclomethasone dipropionate or equivalent daily, median dose $1,600 \mu \mathrm{g}$ ), oral prednisone (median dose $\left.11 \mathrm{mg} \cdot \mathrm{day}^{-1}\right)$, long-acting
Table 1.-Subject characteristics according to asthma control

\begin{tabular}{lcc}
\hline & $\begin{array}{c}\text { Poorly controlled } \\
\text { asthma }\end{array}$ & $\begin{array}{c}\text { Controlled } \\
\text { asthma }\end{array}$ \\
\hline $\begin{array}{c}\text { Subjects n } \\
\text { Asthma symptoms } \\
\text { days·last week }\end{array}$ & $7(4.75-7)^{-1 * * *}$ & $0(0-1)$ \\
$\begin{array}{c}\text { Night waking } \\
\text { due to asthma } \\
\text { nights·last week }\end{array}$ & $5(3.75-7)^{* * *}$ & $0(0-0)$ \\
$\begin{array}{c}\text { Short-acting } \\
\quad \beta \text {-agonist use } \\
\text { occasions } \cdot \text { day }\end{array}$ & $4(2-5.50)^{* * *}$ & $0(0-0.50)$ \\
$\begin{array}{c}\text { Diurnal variability } \\
\text { of PEF \% }\end{array}$ & $25(22.75-26.50)^{* * * *}$ & $5(5-5.50)$ \\
\begin{tabular}{l} 
FEV1 \% pred \\
\hline
\end{tabular} & $77(63-83)$ & $89.50(69-101.75)$ \\
\hline
\end{tabular}

Results are expressed as median (25-75th percentiles) unless otherwise stated. PEF: peak expiratory flow; FEV1: forced expiratory volume in one second. $* * *: \mathrm{p}<0.001$.

$\beta_{2}$-agonists and theophylline. The median age of mild-moderate and severe asthmatics was not significantly different as compared to normal subjects, however, the severe group tended to be older. Baseline FEV1 values were significantly lower in the severe prednisone-dependent group (baseline: median 62\%, 25-75th percentiles $56-66 \%$ ), as compared to mildmoderate asthmatics $(\mathrm{p}<0.05)$, and compared to healthy subjects $(\mathrm{p}<0.001)$.

Table 2.-Subject characteristics according to asthma severity

$\begin{array}{ccc}\begin{array}{c}\text { Normal } \\ \text { subjects }\end{array} & \begin{array}{c}\text { Mild-moderate } \\ \text { persistent } \\ \text { asthma }\end{array} & \begin{array}{c}\text { Severe } \\ \text { persistent } \\ \text { asthma } \\ \text { (prednisone- } \\ \text { dependent) }\end{array} \\ 8 & 23 & 12 \\ 3: 5 & 10: 13 & 8: 4 \\ 29.5 & 38 & 58.5 \\ (26-35.5) & (23-60) & (42-69) \\ 96 & 84 & 62.2 \\ (51-106)^{* * *} & (77-101)^{*} & (55.6-66)\end{array}$

\begin{tabular}{|c|c|c|c|}
\hline \multicolumn{4}{|l|}{$\beta_{2}$-agonists } \\
\hline Short-acting & $\mathrm{NE}$ & + & + \\
\hline Long-acting & & $\begin{array}{c}\text { mild -/ } \\
\text { moderate }+\end{array}$ & + \\
\hline Inhaled steroids & & $\begin{array}{c}500 \mu \mathrm{g} \cdot \mathrm{day}^{-1 \#} \\
(200-1000)\end{array}$ & $\begin{array}{c}1600 \\
\mu \mathrm{g} \cdot \mathrm{day}^{-1 \#} \\
(1600-1875\end{array}$ \\
\hline Oral steroids & & - & $\begin{array}{c}11 \\
\mathrm{mg} \cdot \mathrm{day}^{-1} \\
(3-22.5)\end{array}$ \\
\hline $\begin{array}{l}\text { Poorly controlled/ } \\
\text { controlled }\end{array}$ & $\mathrm{NE}$ & $14 / 9$ & $5 / 7$ \\
\hline Atopy & $\mathrm{NE}$ & 10 & 6 \\
\hline
\end{tabular}

Results are expressed as median (25-75th percentiles) unless otherwise stated. M: male; F: female; FEV1: forced expiratory volume in one second; NE: not evaluable; -: not used; +: used. \#: beclomethasone dipropionate or equivalent daily; : prednisone. $*: \mathrm{p}<0.05 ; * * *: \mathrm{p}<0.001$, differences between all groups and oral corticosteroid group. 


\section{Cells, biochemical mediators and poor asthma control}

When the authors stratified according to the control of the disease, asthmatic patients with poorly controlled asthma had significantly higher sputum eosinophil levels $(\mathrm{p}=0.01)$, ECP levels $(\mathrm{p}=0.05), \mathrm{LTE}_{4}$ levels $(\mathrm{p}=0.05)$ and RANTES levels $(\mathrm{p}=0.04)$, as compared to controlled asthmatics (table 3, fig. 1). Due to lack of supernatant, $\mathrm{LTE}_{4}$ was not measured in two poorly controlled asthmatic subjects. No difference was found in IL-8 levels between controlled and poorly controlled patients.

The evaluation of poorly controlled asthmatics, controlled asthmatics and normal subjects, using the Kruskal-Wallis nonparametric test, showed a significant difference in the total neutrophil number $(\mathrm{p}=0.05)$, total eosinophil number and percentage ( $p=0.004$ and $p=0.003$, respectively) and in the total cell number $(\mathrm{p}=0.02)$. Moreover, there was a significant difference in ECP $(p=0.0001), \mathrm{LTE}_{4}(\mathrm{p}=0.03)$, RANTES ( $p=0.006)$ and IL-8 $(p=0.01)$ levels.

Considering the different parameters of asthma control (symptom scores, night waking, short-acting $\beta_{2}$-agonist requirement and diurnal PEF variability), a correlation between sputum eosinophil percentage and the number of days with symptoms per week was found (Spearman-rank test: rho=0.3; $\mathrm{p}=0.049$ ).

\section{Cells, biochemical mediators and asthma severity}

When the authors stratified according to the severity of asthma, the two groups of asthmatics (mild-moderate and severe prednisone-dependent) had higher sputum eosinophilia (absolute count and percentage) than normal subjects $(\mathrm{p}=0.04)$, without any difference related to asthma severity. Neutrophils were significantly increased in severe prednisone-dependent asthmatics, as compared to mild-to-moderate patients $(\mathrm{p}=0.04)$ and to normal subjects $(\mathrm{p}=0.008)$.

Mild-moderate and severe prednisone-dependent asthmatics had increased levels of $\mathrm{LTE}_{4}$, as compared to normal subjects (mild-moderate versus normals $\mathrm{p}=0.003$; severe prednisone-dependent versus normals $\mathrm{p}=0.03$ ), without any difference according to their severity. ECP measurements showed increased levels in both mild-moderate and severe prednisonedependent subjects, as compared to normal volunteers ( $p=0.004$ and $p=0.003$, respectively). RANTES levels were significantly higher in the mild-moderate group as compared to normal subjects $(\mathrm{p}=0.004)$, but 28 out of 45 samples had levels below the limit of detection for the assay. IL-8 detection demonstrated increased levels in both asthmatic groups, as compared to normal volunteers (mild-moderate versus normals $\mathrm{p}=0.01$; severe prednisone-dependent versus normals $\mathrm{p}=0.004)$, without any difference according to their severity. For all these assays, spiking was performed using a known concentration of each substrate and the same concentration was found after addition of dithiothreitol. To correct for the level of control, sputum eosinophils, ECP and $\mathrm{LTE}_{4}$ in patients with asthma of differing severity but under control were then analysed.

Comparison of controlled asthmatics with mildmoderate persistent asthma and controlled asthmatics with severe prednisone-dependent asthma did not show any difference in sputum eosinophils, ECP and $\mathrm{LTE}_{4}$ levels, suggesting that in controlled asthmatics the characteristics of sputum are independent from the severity of asthma.

\section{Discussion}

In this study it was shown that eosinophils and eosinophilic mediators, such as ECP, $\mathrm{LTE}_{4}$ and

Table 3. - Sputum characteristics according to asthma control

\begin{tabular}{|c|c|c|c|c|}
\hline & Poorly controlled asthma & Controlled asthma & p-value & Normal subjects \\
\hline Total cells $\times 10^{3} \mathrm{~mL}^{-1}$ & $318.3(123.8-775.3)$ & $388.9(252.2-545.3)$ & NS & $153.2(66.4-202.8)$ \\
\hline \multicolumn{5}{|l|}{ Macrophages } \\
\hline Total $\times 10^{3} \mathrm{~mL}^{-1}$ & $223.6(80-533.6)$ & $265.6(136.7-431.5)$ & NS & $62(18.2-80)$ \\
\hline$\%$ & $66.67(48.9-87.2)$ & $86.75(67.8-95)$ & NS & $91(71.5-94)$ \\
\hline \multicolumn{5}{|l|}{ Lymphocytes } \\
\hline Total $\times 10^{3} \mathrm{~mL}^{-1}$ & $5.9(0-10.9)$ & $11.2(1.8-25)$ & NS & $0(0-0.8)$ \\
\hline$\%$ & $1.12(0-4.8)$ & $2.39(0.6-6.3)$ & NS & $0(0-1)$ \\
\hline \multicolumn{5}{|l|}{ Neutrophils } \\
\hline Total $\times 10^{3} \mathrm{~mL}^{-1}$ & $20.9(0-187.5)$ & $9.4(0-53.7)$ & NS & $0(0-3.7)$ \\
\hline$\%$ & $5.77(0-22.6)$ & $3.13(0-9.8)$ & NS & $0(0-4)$ \\
\hline \multicolumn{5}{|l|}{ Eosinophils } \\
\hline Total $\times 10^{3} \mathrm{~mL}^{-1}$ & $9(0-49.6)$ & $0(0-4.1)$ & 0.01 & $0(0-0)$ \\
\hline$\%$ & $2.5(0-20.8)$ & $0(0-1.16)$ & 0.01 & $0(0-0)$ \\
\hline \multicolumn{5}{|l|}{ Epithelial cells } \\
\hline Total $\times 10^{3} \mathrm{~mL}^{-1}$ & $0(0-13.7)$ & $6.6(0-17.7)$ & NS & $3.7(0.2-9.7)$ \\
\hline$\%$ & $0(0-5.66)$ & $2.9(0-8)$ & NS & $5.5(1.5-24)$ \\
\hline $\mathrm{LTE}_{4} \mathrm{pg} \cdot \mathrm{mL}^{-1}$ & $2178.5(1645-2977)$ & $1814.5(1477-2227.5)$ & 0.05 & $650(362-1452)$ \\
\hline $\mathrm{ECP} \mu \cdot \mathrm{L}^{-1}$ & $648.92(406.1-1166.5)$ & $379.731(98.5-812.1)$ & 0.05 & $13.7(4.9-18.4)$ \\
\hline RANTES $\mathrm{pg} \cdot \mathrm{mL}^{-1}$ & $1.41(0-9.8)$ & $0(0-0.66)$ & 0.04 & $0(0-0)$ \\
\hline $\mathrm{IL}-8 \mathrm{pg} \cdot \mathrm{mL}^{-1}$ & 4275 (1073.35-6763.77) & $1502.07(425.27-84620.1)$ & NS & $25.3(17.5-974)$ \\
\hline
\end{tabular}

Results are expressed as median (25-75th percentiles). LTE 4 : leucotriene E4; ECP: eosinophil cationic protein; RANTES: regulated on activation, normal T-cell expressed and secreted; IL-8: interleukin 8. p-Values refer to poorly controlled asthma versus controlled asthma. 

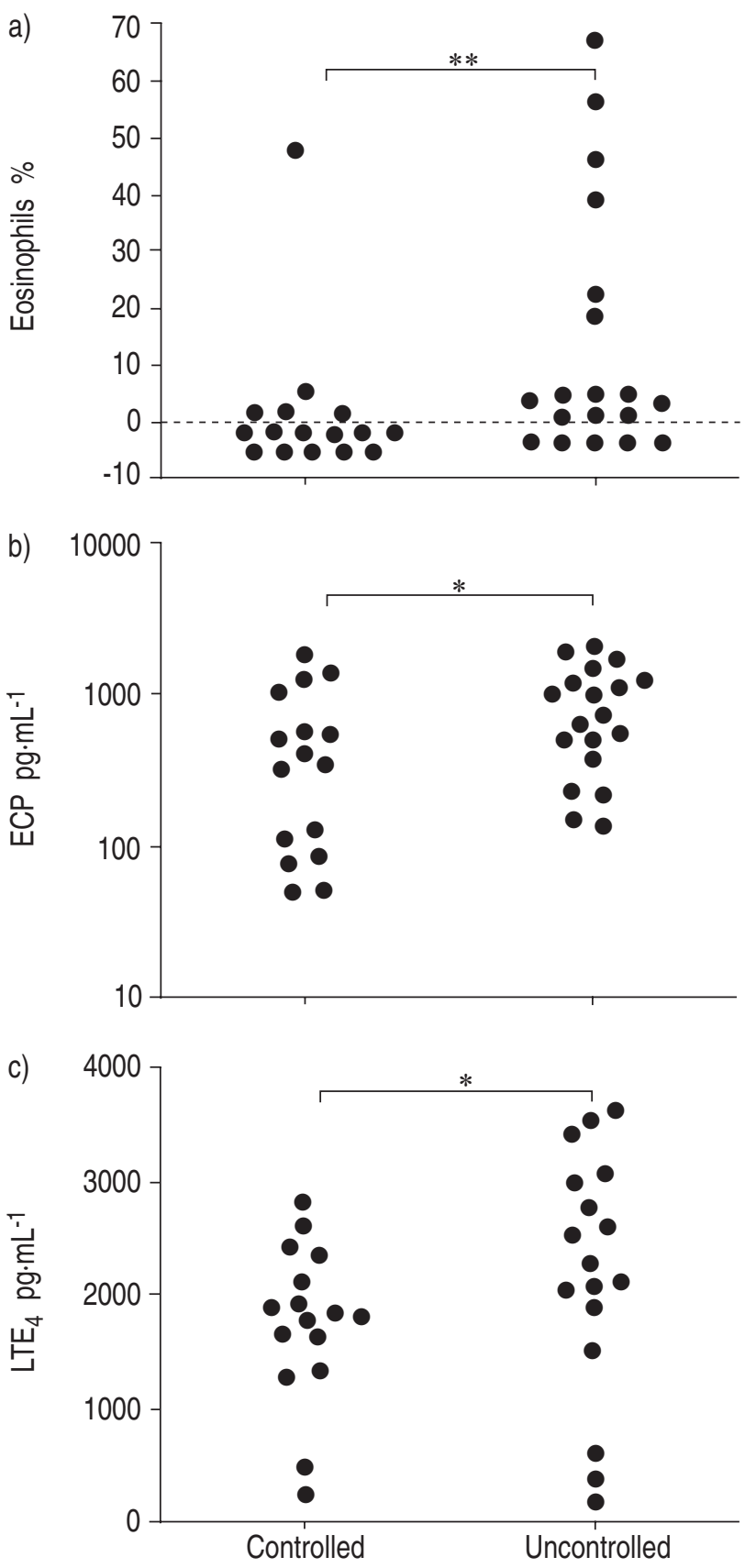

Fig. 1.-a) Sputum eosinophils, b) eosinophil cationic protein (ECP) and leukotriene $\mathrm{E} 4\left(\mathrm{LTE}_{4}\right)$ levels in relation to asthma control. Controlled: patients with controlled asthma; Uncontrolled: patients with poorly asthma control. *: $\mathrm{p}=0.05 ; * *: \mathrm{p}=0.01$.

RANTES, are increased in subjects with poorly controlled asthma independently from the degree of severity chronically assessed. By contrast, eosinophils and eosinophilic mediators are not different in subjects with varying degrees of chronic asthma, if they are examined when they are under control. Thus, airways eosinophilia is associated with poorly controlled asthma and not with the severity of chronic asthma. To the best of the authors' knowledge this is the first study showing that poorly controlled asthma is associated with sputum eosinophilia.
REDDEL et al. [3] recommended the distinction between asthma exacerbations and poorly controlled asthma on the basis of symptoms (symptom frequency, night waking and bronchodilator use) and different PEF behaviours, as they represent two different clinical manifestations of asthma. Poorly controlled asthma is characterised by the presence of ongoing symptoms and/or an increased $(>20 \%)$ diurnal variability of PEF. By contrast, asthma exacerbations are characterised by a detectable change in intensity of symptoms associated with a linear decline of PEF values without changes in PEF variability [3]. The distinction has important clinical implications, as the treatment of poorly controlled asthma simply requires the administration of increasing amounts of inhaled steroids possibly combined with long-lasting bronchodilators, whereas the treatment of exacerbations requires a short course of systemic steroids [1].

In the present study, 19 patients with asthma of different chronic severity, appropriately treated according to their level of severity, were poorly controlled, even if they were not exacerbated [19]. The poorly controlled patients displayed more diurnal and nocturnal symptoms, and they required more rescue medications than well-controlled patients. The only objective sign of poor control of asthma was an increased diurnal PEF variation, whereas FEV1 was not different between poorly controlled and controlled patients.

Inflammation has been assumed to represent an important factor underlying exacerbations of asthma. Previous studies have shown an association between sputum eosinophilia and exacerbations of asthma induced by withdrawal of corticosteroid treatment $[20$, 21]. In the present study, poorly controlled asthma was not due to the withdrawal of anti-inflammatory treatment and it was associated with sputum eosinophilia, suggesting a correlation between eosinophilic airway inflammation and clinical instability of the disease. Eosinophilic inflammation has also been assumed to be an important determinant of the severity of asthma [22, 23]. However, when asthma severity was considered, it was found that even if the eosinophil number and eosinophilic mediators were increased in all groups of asthmatic patients as compared to normal subjects, no difference between patients with different asthma severity, when examined under controlled conditions, was found. The present results are in keeping with the results of the previous studies that did not demonstrate a significant correlation between eosinophilic inflammation and the severity of asthma $[8,11,24]$ and are in contrast to those studies that found a significant correlation between eosinophilic inflammation and the severity of asthma [9, 22]. Thus, the results confirm and extend those of previous studies showing that a transient increase in sputum eosinophilia is associated with loss of control of asthma and that the level of instability must be taken into account in trying to correlate severity with eosinophilic inflammation.

In this study, five out of the total of 19 patients considered to have poorly controlled asthma did not have sputum eosinophilia. Correspondingly, there are several reports demonstrating the presence of frequent 
noneosinophilic inflammation in asthmatic subjects, both in stable and acute conditions [8, 25-27]. When patients with an eosinophilic inflammatory pattern and patients with noneosinophilic inflammation were combined, the median of sputum eosinophils was low $(2.5 \%)$ in the 19 poorly controlled asthmatics. The median of sputum eosinophils was recalculated in the seven patients with eosinophils $>4 \%$ and a median value of $20 \%$ was found, which was quite similar to previous reports during exacerbations. Moreover, it must also be considered that the study patients were not exacerbated asthmatics, but poorly controlled asthmatics, most likely with lower airway inflammation as compared to exacerbations.

The reason why eosinophilia persists despite the use of proper treatment, including steroids, is still unknown. It has been demonstrated recently that two distinct pathological subtypes of severe steroid-dependent asthma exist, one with a near absence of bronchial eosinophils and one with persistent eosinophils, together with increased neutrophils in both groups, supporting the concept of heterogeneity of asthma [8]. Eosinophils are clearly decreased in the bronchial mucosa of severe steroid-dependent asthmatics, as observed on bronchial biopsies [8,28], but despite the treatment, severe asthmatics are still able to recruit endoluminal eosinophils when they became uncontrolled, as shown in the present study.

$\mathrm{LTE}_{4}$ levels were significantly higher in poorly controlled asthmatics than in controlled patients. Increased $\mathrm{LTE}_{4}$ levels have been found after allergen challenge in atopic asthmatics [29] and after aspirin challenge in subjects with aspirin intolerance [30]. Recently, a significantly higher sputum $\mathrm{LTC}_{4} / \mathrm{D}_{4} / \mathrm{E}_{4}$ concentration was found in mild-to-moderate asthma treated with inhaled steroids or during an acute exacerbation [31]. Thus, the observed sputum eosinophilia might be due to the local release of $\mathrm{LTE}_{4}$. The presence of high levels of $\mathrm{LTE}_{4}$ even in more severe steroid-dependent patients supports the theory that corticosteroids do not directly reduce cysteinyl-leukotriene production [32].

When ECP levels in sputum supernatant were considered, a relationship with the poor control of asthma was found, further supporting the role of eosinophils. No differences in the ECP levels between the different groups of asthmatics were observed, in particular, higher levels of ECP in more severe asthmatics was not found, as reported previously [12]. This discrepancy is probably due to the heterogeneity of the asthmatic population, including patients with and without airway eosinophils, depending on asthma control.

In the present study, patients' sputum neutrophils were not related to the degree of control of asthma. When the severity of the disease was considered, it was observed that severe steroid-dependent asthmatics had sputum neutrophilia, as compared to asthmatics with mild-to- moderate asthma. This result suggests that neutrophils might be more related to the severity of chronic asthma than eosinophils [8, 28, 33]. Neutrophils have been found in chronic severe persistent asthma [8, 28, 33, 34], nocturnal asthma [35, 36], severe asthma exacerbations [37], status asthmaticus [38] and in asthma death [39, 40].

The median neutrophil count of the patients was surprisingly very low in this study $(3 \%)$. As the neutrophil levels were very low in all the groups studied, they might not be a confounding factor interfering with the results. Some of the patients (a small minority) had very high neutrophil values, showing a high variability in the neutrophil count. It has been shown that in normal subjects [41] and in asthmatics during stable [26] and acute conditions [27] the sputum neutrophil count is very variable, with a few subjects presenting with very low values.

The low levels of neutrophils and the higher levels of macrophages that were found may be explained by the fact that in the present study, induction of sputum was performed during a longer period $(\geqslant 20 \mathrm{~min}$ inhalation $\leqslant 30 \mathrm{~min}$ ), as previously described by other authors. It has been demonstrated that the induction of sputum by consecutive sampling periods $(\leqslant 30 \mathrm{~min})$ of a single induction procedure induces significant changes in cellular composition, in particular with a decrease in neutrophils and an increase in macrophages [42].

The reason for the poor control of asthma, in the present patients is not known. A recent study has shown that acute exacerbations of asthma induced by viral infections have increased sputum neutrophils [43]. The patients were probably not experiencing a viral infection as they only had very few neutrophils, however, the authors did not have results on the aetiology.

To conclude, the data presented here suggest that sputum eosinophilia and eosinophilic markers are associated with poor asthma control rather than with the severity of asthma. As sputum eosinophilia is associated with a positive clinical and functional response to steroids, the results support the recommendation to increase the dose of steroids when asthma becomes uncontrolled. However, there are still $25 \%$ of subjects without sputum eosinophilia who are poorly controlled. Whether this subgroup is less responsive to steroids remains to be established.

Acknowledgements. The authors would like to thank L. Fabbri for thoughtful contributions to this manuscript.

\section{References}

1. Global Strategy for Asthma Management and Prevention. NIH publication no. 02-3659. Updated from: NHLBI/WHO Workshop Report: Global Strategy for Asthma Management and Prevention Issued January, 1995. 2002.

2. Godard P, Clark TJH, Busse WW, et al. Clinical assessment of patients. Eur Respir J 1998; 11: Suppl. $26,2 \mathrm{~s}-5 \mathrm{~s}$.

3. Reddel H, Ware S, Marks G, Salome C, Jenkins C, Woolcock A. Differences between asthma exacerbations and poor asthma control. Lancet 1999; 353: 364 369. (published erratum appears in Lancet 1999; $353: 758)$. 
4. Vollmer WM, Markson LE, O'Connor E, et al. Association of asthma control with health care utilization and quality of life. Am J Respir Crit Care Med 1999; 160: 1647-1652.

5. Juniper EFK, Svensson P, O'Byrne M, et al. Asthma quality of life during 1 year of treatment with budesonide with or without formoterol. Eur Respir $J$ 1999; 14: 1038-1043.

6. Boulet LP, Becker A, Berube D, Beveridge R, Ernst P. Canadian Asthma Consensus Report, 1999. Canadian Asthma Consensus Group. Can Respir J 1999; 161: Suppl. 11, S1-61.

7. Juniper EF, O'Byrne PM, Ferrie PJ, King DR, Roberts JN. Measuring asthma control. Clinic questionnaire or daily diary? Am J Respir Crit Care Med 2000; 162: 1330-1334.

8. Wenzel SE, Schwartz LB, Langmack EL, et al. Evidence that severe asthma can be divided pathologically into two inflammatory subtypes with distinct physiologic and clinical characteristics. Am J Respir Crit Care Med 1999; 160: 1001-1008.

9. Louis R, Lau LC, Bron AO, Roldaan AC, Radermecker M, Djukanovic R. The relationship between airways inflammation and asthma severity. Am J Respir Crit Care Med 2000; 161: 9-16.

10. Grootendorst DC, van den Bos JW, Romeijn JJ, et al. Induced sputum in adolescents with severe stable asthma. Safety and the relationship of cell counts and eosinophil cationic protein to clinical severity. Eur Respir J 1999; 13: 647-653.

11. Tarodo de la Fuente P, Romagnoli M, Carlsson L, Godard P, Bousquet J, Chanez P. Eosinophilic inflammation assessed by induced sputum in corticosteroiddependent asthma. Respir Med 1999; 93: 183-189.

12. Jatakanon A, Uasuf C, Maziak W, Lim S, Chung KF, Barnes PJ. Neutrophilic inflammation in severe persistent asthma. Am J Respir Crit Care Med 1999; 160: 1532-1539.

13. Pauwels RA, Lofdahl CG, Postma DS, et al. Effect of inhaled formoterol and budesonide on exacerbations of asthma. Formoterol and Corticosteroids Establishing Therapy (FACET) International Study Group. $N$ Engl J Med 1997; 337: 1405-1411. (published erratum appears in $N$ Engl $\mathrm{J}$ Med 1998; 338:139).

14. de la Fuente PT, Romagnoli M, Godard P, Bousquet J, Chanez P. Safety of inducing sputum in patients with asthma of varying severity. Am J Respir Crit Care Med 1998; 157: 1127-1130.

15. Aas K. Heterogeneity of bronchial asthma. Subpopulations or different stages of the disease. Allergy 1981; 36: 3-14.

16. Pin I, Freitag AP, $\mathrm{O}^{\prime}$ Byrne PM, et al. Changes in the cellular profile of induced sputum after allergeninduced asthmatic responses. Am Rev Respir Dis 1992; 145: 1265-1269.

17. Pin I, Gibson PG, Kolendowicz R, et al. Use of induced sputum cell counts to investigate airway inflammation in asthma. Thorax 1992; 47: 25-29.

18. Chavis C, Godard P, Michel FB, Crastes de Paulet A, Damon M. Sulfidopeptide leukotrienes contribute to human alveolar macrophage activation in asthma. Prostaglandins Leukot Essent Fatty Acids 1991; 42: 95100.

19. Cockcroft DW, Swystun VA. Asthma control versus asthma severity. J Allergy Clin Immunol 1996; 98: 1016-1068.

20. Pizzichini MM, Pizzichini E, Clelland L, et al.
Prednisone-dependent asthma: inflammatory indices in induced sputum. Eur Respir J 1999; 13: 15-21.

21. Jatakanon A, Lim S, Barnes PJ. Changes in sputum eosinophils predict loss of asthma control. Am J Respir Crit Care Med 2000; 161: 64-72.

22. Bousquet J, Chanez P, Lacoste JY, et al. Eosinophilic inflammation in asthma. N Engl J Med 1990; 323: 1033-1039.

23. Busse WW. Inflammation in asthma: the cornerstone of the disease and target of therapy. J Allergy Clin Immunol 1998; 102: S17-S22.

24. Jatakanon A, Kharitonov S, Lim S, Barnes PJ. Effect of differing doses of inhaled budesonide on markers of airway inflammation in patients with mild asthma. Thorax 1999; 54: 108-114.

25. Pizzichini E, Pizzichini MM, Efthimiadis A, Dolovich J, Hargreave FE. Measuring airway inflammation in asthma: eosinophils and eosinophilic cationic protein in induced sputum compared with peripheral blood. J Allergy Clin Immunol 1997; 99: 539-544.

26. Gibson PG, Simpson JL, Saltos N. Heterogeneity of airway inflammation in persistent asthma: evidence of neutrophilic inflammation and increased sputum interleukin-8. Chest 2001; 119: 1329-1336.

27. Gibson PG, Norzila MZ, Fakes K, Simpson J, Henry RL. Pattern of airway inflammation and its determinants in children with acute severe asthma. Pediatr Pulmonol 1999; 28: 261-70.

28. Chanez P, Vignola AM. Changes in bronchial inflammation of steroid (GCs) dependent asthmatics. Am J Respir Crit Care Med 1996; 153: A212.

29. Taylor GW, Taylor I, Black P, et al. Urinary leukotriene E4 after antigen challenge and in acute asthma and allergic rhinitis. Lancet 1989; 1: 584-588.

30. Christie PE, Tagari P, Ford-Hutchinson AW, et al. Urinary leukotriene E4 concentrations increase after aspirin challenge in aspirin-sensitive asthmatic subjects. Am Rev Respir Dis 1991; 143: 1025-1029.

31. Pavord ID, Ward R, Woltmann G, Wardlaw AJ, Sheller JR, Dworski R. Induced sputum eicosanoid concentrations in asthma. Am J Respir Crit Care Med 1999; 160: 1905-1909.

32. Dworski R, Fitzgerald GA, Oates JA, Sheller JR. Effect of oral prednisone on airway inflammatory mediators in atopic asthma. Am J Respir Crit Care Med 1994; 149: 953-959.

33. Wenzel SE, Szefler SJ, Leung DY, et al. Bronchoscopic evaluation of severe asthma. Persistent inflammation associated with high dose glucocorticoids. Am J Respir Crit Care Med 1997; 156: 737-743.

34. Chanez P, Enander I, Jones I, Godard P, Bousquet J. Interleukin 8 in bronchoalveolar lavage of asthmatic and chronic bronchitis patients. Int Arch Allergy Immunol 1996; 111: 83-88.

35. Kraft M, Torvik JA, Trudeau JB, Wenzel SE, Martin RJ. Theophylline: potential antiinflammatory effects in nocturnal asthma. J Allergy Clin Immunol 1996; 97: 1242-1246.

36. Wenzel SE, Trudeau JB, Westcott JY, Beam WR, Martin RJ. Single oral dose of prednisone decreases leukotriene B4 production by alveolar macrophages from patients with nocturnal asthma but not control subjects: relationship to changes in cellular influx and FEV1. J Allergy Clin Immunol 1994; 94: 870-881.

37. Fahy JV, Kim KW, Liu J, Boushey HA. Prominent neutrophilic inflammation in sputum from subjects 
with asthma exacerbation. J Allergy Clin Immunol 1995; 95: 843-852.

38. Lamblin C, Gosset P, Tillie-Leblond I, et al. Bronchial neutrophilia in patients with noninfectious status asthmaticus. Am J Respir Crit Care Med 1998; 157: $394-402$.

39. Carroll N, Carello S, Cooke C, James A. Airway structure and inflammatory cells in fatal attacks of asthma. Eur Respir J 1996; 9: 709-715.

40. Sur S, Crotty TB, Kephart GM, et al. Sudden-onset fatal asthma. A distinct entity with few eosinophils and relatively more neutrophils in the airway submucosa? Am Rev Respir Dis 1993; 148: 713-719.
41. Belda J, Leigh R, Parameswaran K, O'Byrne PM, Sears MR, Hargreave FE. Induced sputum cell counts in healthy adults. Am J Respir Crit Care Med 2000; 161: 475-478.

42. Holz O, Jorres RA, Koschyk S, Speckin P, Welker L, Magnussen $\mathrm{H}$. Changes in sputum composition during sputum induction in healthy and asthmatic subjects. Clin Exp Allergy 1998; 28: 284-292.

43. Wark PA, Johnston SL, Moric I, Simpson JL, Hensley MJ, Gibson PG. Neutrophil degranulation and cell lysis is associated with clinical severity in virus-induced asthma. Eur Respir $J$ 2002; 19 68-75. 